\title{
ITALIANOS EM NÚCLEOS URBANOS E NA CAPITAL DO RIO GRANDE DO SUL ENTRE 1826 E 1875
}

\author{
Núncia Santoro de Constantino*
}

Com a implantação dos núcleos coloniais na Encosta do Nordeste do Rio Grande do Sul, a partir de 1875 , amplia-se significativamente a presença de italianos na Província de São Pedro. Portanto, desde aquele ano, podese constatar duas formas de permanência entre o grupo peninsular: a imigração colonizadora, essencialmente agrícola, patrocinada ou incentivada pelo governo; a presença espontânea, bem anterior, cujos elementos fixaram-se nos núcleos urbanos desde as primeiras décadas do século XIX. No final do século passado, surgiria outra modalidade de imigração, também espontânea, mas que tinha a finalidade de suprir a escassez de mão-de-obra. Tal modalidade, como a colonizadora, era incentivada pelo governo que atendia a demanda de serviços frente ao crescimento da zona urbana e a diminuição do número de escravos.

Sabe-se que os italianos estiveram sempre presentes no Brasil e já são encontrados nos núcleos urbanos do período colonial.

Escreve Manuel Diégues Júnior sobre os italianos:

\begin{abstract}
"Não aqui vindos como imigrantes, às vezes até mesmo como conquistadores, muitos se integram na vida brasileira. Um Cristóvão Luís, um Filippo Cavalcanti, um Barbi, um Líbero Badaró, por exemplo."1
\end{abstract}

Com referência aos italianos, percebe-se que, nas zonas urbanas, exercem atividades artísticas, técnicas ou comerciais, assim como podem prestar serviços militares e, posteriormente, quando fazem parte de contingentes de imigração, desenvolvem serviços que têm relação com o trabalho escravo: aguadeiros, quitandeiros, engraxates, vendedores ambulantes. Estes últimos, em geral, são provenientes das regiões meridionais como Basilicata, Sicilia, Campania, Puglia e, principalmente, Calábria.

$\mathrm{O}$ que se pretende no presente trabalho é apresentar dados históricos sobre a presença italiana em núcleos urbanos do Rio Grande do Sul antes de 
1875, com destaque à cidade de Porto Alegre, assim como analisar fatores que contribuíram para tal presença.

Iniciou-se a investigação sobre a presença de Italianos em Porto Alegre através dos Livros de Batismo preservados no Arquivo da Cúria Metropolitana. Assim, foi possível verificar que, desde 1826, há registros de crianças descendentes, batizadas nas três paróquias da cidade: Nossa Senhora Madre de Deus, Nossa Senhora do Rosário e Nossa Senhora das Dores.

Pode-se arrolar, na primeira metade do século XIX, os seguintes nomes: Rafaela Magnoni, nascida em outubro de 1826; Leopoldina, Joaquim, Idalina e Maria Luíza Francioni; Julio Friziani; João Favaro, João Sabatoni, José Limoni, nascido em agosto de 1847.

Mais evidências desta presença são encontradas no jornal " $O$ Imparcial"', ${ }^{2}$ de 22 de fevereiro de 1845 , quandoé registrada a nota de falecimento de Rafael Ascoli, que residiu à Rua da Praia. No mesmo exemplar há propaganda do atelier fotográfico do Sr. Masoni, cuja grafia do nome não deixa dúvidas quanto à origem.

Antes de 1850, o grupo de italianos vivendo em Porto Alegre é pequeno, mas há indício documental de que monopolizava o comércio de carnes em prejuízo dos consumidores. ${ }^{3}$

Ainda nos meados do século passado, registra-se a atuação do pintor Bernardo Grasseli que realizou trabalhos artísticos de excelente nível como a decoração do Teatro São Pedro, inaugurado em 1858, e o re trato a óleo do General Canabarro. ${ }^{4}$

A ata da Câmara Municipal referente a 16 de outubro de 1851 registra solicitação de João Baptista Blengini, no sentido de obter licença "para armar barraca espaçosa ao lado da Socie dade Bailante para estabelecer negócio nas festividades de Natal e Pentecostes."

A partir da década de 1860 , percebe-se o progressivo crescimento do grupo de italianos no Rio Grande do Sul.

Nas paróquias de Porto Alegre, entre 1862 e 1865, são batizadas as seguintes crianças, descendentes de italianos: Victor Blengini Obino, Benigna Schiafino, Luíza Ratto, José Tohino, Apollonia Olisier, João Martino Varone, Antonio Carbone Amoretti, Miguel Schiafino Muratore, João Affonso Pratti, Jacques, Antonia e Maria Viale.

A correspondência entre agentes consulares italianos, estabelecidos na Província por volta de 1860 , e os Presidentes da mesma é rica em elementos que nos proporcionam conhecimento sobre as condições de vida, os problemas enfrentados, as atividades econômicas desenvolvidas pelos súditos da Itália. $^{5}$

Através de tal correspondência, sabe-se que, em 1861, o delegado consular reclama o espólio de súdito italiano, espólio que fora recolhido pelo 
Juiz de Órfãos e Ausentes de Alegrete. Em 1863, o vice-cônsul também reclama a herança do súdito Soragni, de São Borja, cujo único herdeiro teve o espólio recolhido pela Tesouraria da Fazenda da Província.

João Baptista Amoretti, estabelecido com "Fábrica de Padaria" à Rua Riachuelo, no ano de 1866 , encaminha pedido de isenção do serviço militar na Guarda Nacional para seu filho Francisco, por ser o mesmo fitho de súdito da Itália. À mesma época, queixa-se Luiz Risso porque lhe aprenderam "in devidamente" mercadorias em São Borja.

Em 1867, a Agência Consular encaminha pedido de Pasquale Brande que solicita a Sua Majestade "passagem de proa no fim do mês para o Rio de Janeiro como esmola". Brande havia sido condenado e cumprido pena em Alegrete, fora perdoado e, ao encaminhar a solicitação, declara-se velho e doente.

Na correspondência relativa a 1868 , súditos italianos residentes em Itaqui reclamam do governo indenização por danos à propriedade perpretados pelos invasores paraguaios. Em 1874, a correspon dência acusa o roubo e assassinato do mascate Michele Álbano, cujo cadáver mutilado fora encontrado no município de Piratini. Em 1875, através do Consulado, Andrea Valli solicita alguma resposta do Imperador, com referência ao "estojo de tintas odofíficas" que teria inventado e cujo modelo enviou a D. Pedro II.

Fora criada, em 1871, a Agência Consular de Rio Grande e, em virtude da Lei do Ventre Livre, súditos italianos residentes na Província, em número de 406, enviam, através do agente, cumprimentos ao Impera dor.

Com tantos italianos na Província, não é de estranhar-se que, já em 1877, estivesse fundada a primeira sociedade italiana em Porto Alegre que, de início, foi denominada "Mutuo Soccorso e Benevolenza" e que passou a chamar-se "Vittorio Emanuelle IIO " em 1878. Tem como fundadores: Bartolomeo Pellerini, Luigi Terragno, Paolo Rondelli, Adriano e Domenico Pittanti, Gioachino Ariagno, Pellegrino Cavedagni, Raffaelle Florio, Serafino Pellerini, Constan tino Malnatti, Antonio Raffo, Carlo Preda, Giovanni Cariboni, Carlo Donati, Giovanni Viacava, Francesco Bocacce, Pasquale de Gregorio, Pasquale Lessa, Bartolomeo Vescia e Domenico Viale. ${ }^{6}$

Apresentadas evidências da presença italiana em núcleos urbanos do Rio Grande do Sul, procura-se analisar fatores que a justifiquem.

Parece pertinente lembrar o estudo de Antonio Gramsci que abor da a questão do cosmopolitismo ou a "função cosmopolita" dos intelectuais italianos. Escreve o referido autor:

"Os intelectuais e os especialistas italianos eram cosmopolitas e não italianos, não nacionais. Homens de Estado, capitães, almirantes, cientistas, navegadores italianos não tinham um caráter nacional, mas sim cosmopolita."7 
No Rio Grande do Sul este cosmopolitismo pode ser argumentado a partir dos religiosos que exerceram suas funções desde os primeiros tempos.

Quando, em 1737, inicia-se a empresa para ocupar o território com a fundação do Presídio Jesus Maria José, capuchinhos italianos encontram-se entre os portugueses. Escreve Mansueto Bernar di:

"...para o pastoreio das almas vieram dois padres barbudinhos: Pe. Antonio de Perusa e Pe. Anselmo de Castelvetrano, que pouco demoraram na fortaleza. Mas cabe-lhes o mérito de haver celebrado os primeiros ofícios no Rio Grande português." 8

O mesmo autor lembra que, em 1767, quando a Companhia de Jesus foi expulsa do Brasil, havia 17 padres italianos nas Missões.

Um dos primeiros párocos do Rio Grande do Sul foi o Padre Prospero de Santa Teresa, carmelita, que exerceu ministério em Conceição do Arroio a partir de 1825; o Padre Francesco Ponziglione foi coadjutor na Igreja do Rosário, em Porto Alegre, durante 1846. ${ }^{9}$

Militares italianos, "especialistas" na visão de Gramsci, marcaram presença, de igual modo, no Rio Grande do Sul. É o caso de Garibaldi, Rossetti, Zambecari e Anzani, assim como outros tantos, menos conhecidos, como Mutru, Carniglia, Staderini e Nadone que pereceram no naufrágio do Lanchão "Rio Pardo", nas costas de Santa Catarina. ${ }^{10}$ Cláudio Moreira Bento aponta ainda outros nomes: Valerigni, Cuneo e Nodola. ${ }^{11}$

Antes da Revolução Farroupilha, a presença de italianos "especialistas" entre os militares pode ser encontrada nos trabalhos das partidas de demarcação posteriores ao Tratado de Madri. Nelas encontravam-se o astrônomo Joăo Angelo Brunelli, os engenheiros Henrique Antonio Galluzzi e Domingos Sanbucetti, o desenhista cartógrafo José Landi e o cirurgião Pagliani. $^{12}$.

Artistas plásticos, músicos, cientistas - enfim especialistas - atestam com sua presença o "cosmopolitismo" italiano que, certamente, recebeu impulso através do casamento de D. Pedro II com a princesa napolitana D. Teresa Cristina. Dante de Laytano lembra que, no séquito da futura Imperatriz, havia músicos, cantores, pintores, decoradores, médicos e literatos. ${ }^{13}$

Autores que escrevem sobre as artes no Rio Grande do Sul ${ }^{14}$ destacam nomes como o dos escultores Adriano e Domenico Pittanti, sendo que o primeiro é autor da estátua do Conde de Porto Alegre; Carlos Fossati, cujas obras enriquecem cemitérios e residências da segunda metade do século XIX. Há memória de expoentes da pintura como Eduardo de Martino que, em torno de 1873, colheu flagrantes da Guerra do Paraguai e registrou-os em telas como "Passagem de Humaitá" e "Combate Naval do Riachuelo". 
Lembra-se ainda Bernardo Grasselli, a quem já se fez menção, e que, segundo Walter José Faé, decorou o "Café da Fama", à Rua Nova nọ 40, "primeiro estabelecimento de reunião social da cidade, iniciativa de Joăo Baptista Blengini'. ${ }^{15} \mathrm{O}$ referido autor registra a participação de Grasselli na Exposição Comercial e Industrial de 1875 , em Porto Alegre, com quatro telas a óleo.

Na música destacam-se Luigi Cavedagni, promovendo atuações líricas na década de 1860, e o Professor Luigi Roberti, diretor da sociedade musical "Estudantina Porto-Alegrense", em plena atividade em 1888 e que publicava revista de razoável circulação.

Além do "universalismo" que teria impulsionado a vinda e a eventual permanência de italianos no Rio Grande do Sul, outros fatores podem ser apontados. Escreve Spencer L. Leitman:

\footnotetext{
"Buenos Aires, Montevidéu e Rio de Janeiro possuíam núcleos consideráveis de imigrantes italianos na década de 1820 . Pela década de 1830 , os italianos controlavam o sistema de navegação intema no Rio da Prata e eram membros fixos das tripulações dos barcos de comércio costal de cabotagem na América do Sul."16
}

Através da informação de Leitman, pode-se explicar porque houve concentração numérica dos peninsulares nos núcleos urbanos fronteiriços da Província; tal concentração pode ser detectada pela correspon dência consular que se aborda em linhas anteriores.

Lembra-se, ainda, das importantes observações do Conde D'Eu, ao visitar a Vila de Sant'Ana do Livramento. São palavras do seu diário de viagem, escritas em 11 de outubro de 1865:

\footnotetext{
"A população é, pelo que me dizem, de 2000 almas, de que o elemento brasileiro não representa senão aproximadamente metade, sendo o mais orientais, argentinos e europeus. Entre estes parecemme predominar os italianos. As lojas têm bustos do rei Victor Manuel, de porcelana de cores, e o bilhar da terra tem a tabuleta 'Hotel à La Garibaldi"'. 17
}

Sendo "membros fixos das tripulações dos barcos de comércio" não deve causar admiração que muitos italianos exercessem atividades em Porto Alegre desde a primeira metade do século XIX. Esta cidade, segundo Francisco Riopardense de Macedo, tem importância comercial a partir de 1814, como "esquina da Província" e está recebendo e enviando mercadorias necessárias aos "crescentes centros povoados em torno de Rio Pardo". ${ }^{18}$

Como se vê, uma série de fatores combinados podem explicar a presença dos italianos na capital do Rio Grande do Sul: "universalismo", casa- 
mento do Imperador com princesa napolitana, controle do sistema de navegação in terna no Rio da Prata e participação de tripulantes italianos nos barcos de comércio, além da importância comercial de Porto Alegre.

É possivel, através da documentação compulsada e com auxilio da escassa bibliografia que oferece subsídios para o estudo dos italianos nos núcleos urbanos do Rio Grande do Sul, apontar-se o número de 41 familias que estiveram vivendo em Porto Alegre antes de 1875, quan do aportaram os primeiros colonos italianos. Estas famílias formam grupo relativamente fechado, o que se percebe através da baixa incidência de casamentos mistos. Percebe-se também que, nos registros de batismo, mais de $90 \%$ dos padrinhos são italianos. Por fim, dá-se ênfase ao fato de que a sociedade italiana foi fundada em 1877.

Este grupo já considerável seria ainda muito aumentado a partir da década de 1870, pelos meridionais, em especial calabreses que se concentraram na capital da Província e em determinados quarteirões. Era a imigração italiana espontânea que incluiria milhares de indivíduos antes da virada do século. Tal modalidade de imigração ora se investiga.

\section{NOTAS}

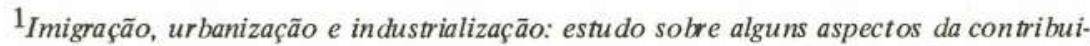
ção cultuml do imigrante no Brasil. Rio de Janeiro, Centro de Pesquisas Educacionais/ INEP/MEC, 1964, p.21.

${ }^{2}$ Museu de Comunicação Social "Hipólito José da Costa". Porto Alegre.

${ }^{3}$ A ta de reunião da Câmara Municipal de Porto Alegre, 12 de janeiro de 1839, Arquivo particular de Sérgio da Costa Franco: "Sendo lido um ofício do Juiz de Paz do Primeiro distrito desta cidade com data de 11 do corrente participando que ao romper do dito dia fora aos talhos públicos da mesma e fazendo pesar a carne que dele saía não encontrou um só peso exato e todos em grandes faltas, porém isto o não admirava por ser cos tume entre os italianos empregados neste tráfego roubar quanto podem."

${ }^{4}$ Anngelo Guido. "As artes plásticas no Rio Grande do Sul". In: Anais do II Congresso Sul-Riograndense de História e Geografia. 4 ? volume, Porto Alegre, Prefeitura Municipal, 1940, p.2107.

${ }^{5}$ Veja-se Arquivo Histórico do Rio Grande do Sul. Consulado da Itália, maço 13.

6 Älbum Cinquantenario della colonizzazione italiana nello Stato del Rio Grande del Sud. Ministero Italiano degli Affari Esteri. Porto Alegre, Livraria do Globo, 1925, p. 365 .

${ }^{7}$ Os intelectuais e a organização da cultura. Rio de Janeir o, Civilização Brasileira, 1982. p.68.

${ }^{8}$ Colonias e colonizadores. Por to Alegre, Sulina/Escola Superior de Teologia São Lourenço de Brindes, 1982. p. 77. 
${ }^{9}$ Älbum Cinquantenario della colonizzazione italiana nello Stato del Rio Grande del Sud. p.135-136.

${ }^{10}$ Mansueto Bemardi. "Italianos e a República de Piratini". In: Cinquantenario della colonizzazione italiana nello Stato del Rio Grande del Sud. p.43.

${ }^{11}$ Estrangeiros e descendentes na História Militar do Rio Grande do Sul - 1635 a 1870. Porto Alegre, A Nação/IEL, 1976. p.227.

12 Mansueto Bernardi. Colonias e colonizadores. P. Alegre, Sulina/Escola Superior de Teologia São Lourenço de Brin des, 1982. p.89.

13 "Notas históricas sobre relações entre Brasil e Itália". In: Imigraçāo Italiana: estudos. Porto Alegre, Escola Superior de Teologia São Lourenço de Brindes; Caxias do Sul, Universidade de Caxias do Sul, 1979.

${ }^{14}$ Ângelo Guido, Antônio Hohlfeldt, Athos Damasceno Ferreira, Enio de Freitas e Castro, Leandro Telles.

${ }^{15}$ Italianos no Rio Grande do Sul? 1875/1975. Americana (SP), Focam, 1975. p.160. 16 "Revolucionários italianos no Império do Brasil". In: A Revolução Farroupilha: História e interpretação. Org. José Hildebrando Dacanal. Porto Alegre, Mercado Aberto, 1985. p.101.

17 In: Ivo Caggiani. Sant'Ana do Livnamento: 150 anos de História. Sant'Ana do Livramento, ASPES, 1983. p.72.

18 Porto Alegre: origem e crescimento. P. Alegre, Sulina, 1968. p.77.

*Pontifícia Universidade Católica do Rio Grande do Sul Departamento de História 90.620 Porto Alegre - RS 